\title{
LA NARRATIVA DE LISÍMACO CHAVARRÍA
}

Recibido: $30-08-2016$

Aprobado: 15-09-2016

\author{
Francisco Rodríguez Cascante \\ Universidad de Costa Rica, Sede de Occidente
}

\section{Resumen}

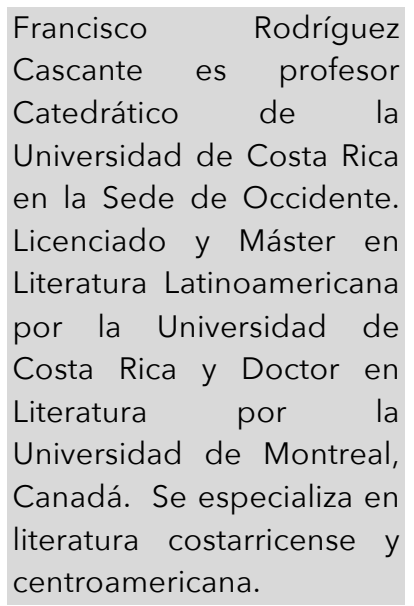

La narrativa del escritor modernista costarricense Lisímaco Chavarría Palma (1873-1913) es un entramado discursivo que articula tres orientaciones. La primera tiene que ver con textos de carácter costumbrista. En esta tendencia se ubican: "Incidentes de don Pancracio (1901), "Serenata campestre" (1903) y "Dormido" (1905). La segunda tendencia agrupa textos con referencias intertextuales clásicas, todos, menos "Omar, el pescador" (1902) publicados en Nómadas (1905): "Venganza de Isis", "Triunfo de Cleopatra" y "Artémida". La tercera orientación consiste en relecturas bíblicas, también textos de Nómadas: "Susana", "El bautista", "Magdalena", "El buen ladrón", "En Gethsemaní" y "En el tabor".

En este artículo se estudian estos tres caminos de la narrativa escrita por Lisímaco Chavarría. En primer lugar, se presta atención a los relatos costumbristas y a sus preocupaciones estéticas e ideológicas, para, posteriormente, analizar las representaciones orientalistas del segundo grupo de relatos. En este nivel, se da cuenta de las fuentes de tales discursos y de sus reelaboraciones de personajes y acontecimientos históricos. Finalmente, se consideran los cuentos que efectúan relecturas de pasajes y personajes bíblicos, para enfatizar dos vertientes: una que se distancia del texto original para amplificar, mediante la erotización, la imagen de la mujer; y otra que se apega más al modelo sagrado con el fin de insistir en el paradigma moral de dicho texto.

Palabras clave: literatura costarricense, modernismo, narrativa breve, Lisímaco Chavarría Palma.

\begin{abstract}
The narrative written by modernist Costa Rican writer Lisímaco Chavarría Palma (18731913 ) is a discursive framework which articulates three orientations. The first has to do with texts of a mannerism nature. In this tendency, we can locate "Incidentes de don Pancracio (Incidentes by Sir. Pancracio; 1901), "Serenata campestre" (Rural Life Seranade; 1903), and "Dormido" (Asleep; 1905). The second tendency lumps together classic texts with inter-textual references, all but "Omar, el pescador" (Omar, the fisherman; 1902) published in Nómadas (1905): "Venganza de Isis" (Isis vengenace), "Triunfo de Cleopatra" (Cleopatra s victory), and "Artémida". The third orientation consists of re-biblical readings as well as texts from Nómadas: "Susana", "El bautista" (The Baptist), "Magdalena", "El buen ladrón" (The Good Theif), "En Gethsemaní" (In Getsemani), and "En el tabor" (In Tabor).

This article studies these three narrative paths written by Lisímaco Chavarría. Firstly, attention is paid to the manner tales and to his ideological and aesthetic preoccupations to, secondly, analyze the Western representations in the second group of stories. At this level, it becomes aware about the origin of such discourse and about its re-reading of characters and historical events. Finally, the article includes an analysis of the stories
\end{abstract}


which constitute re-readings of biblical settings and characters to emphasize two standpoints: one which distances itself from the original text in order to amplify, through erotism, the female image; another which sticks more to the sacred model with the purpose of insisting in a moral paradigm of the sacred text.

Key words: Costa Rican literatura, modernism, short narrative, Lisímaco Chavarría Palma.

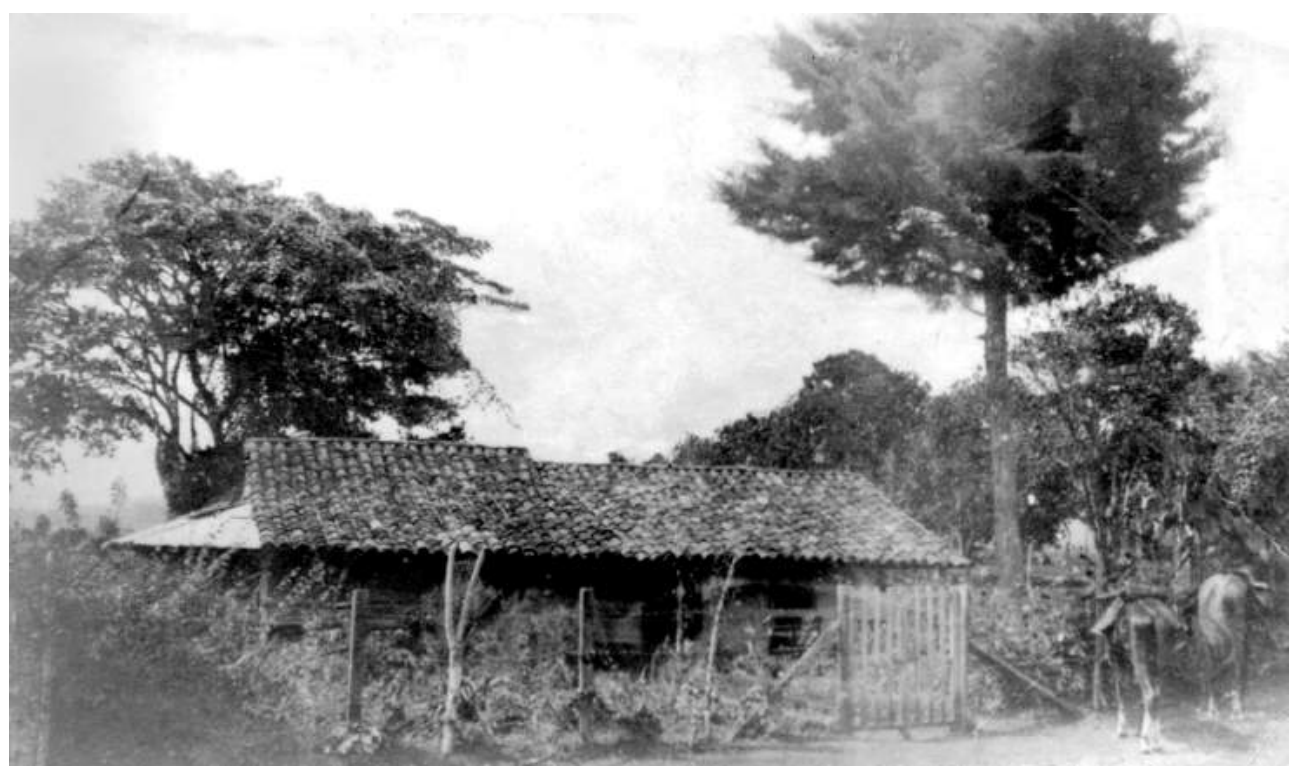

Foto 1: Casa donde nació el poeta. En: María Isabel Araya Coronado. Biografía y obra de Lisímaco Chavarría Palma. Tesis. Escuela de Letras y Filosofía. Universidad de Costa Rica, 1950, página 7.

\section{INTRODUCCIÓN}

Por su amplia producción lírica, el ejercicio narrativo no constituyó el principal centro de atención en la obra literaria del escritor modernista costarricense Lisímaco Chavarría; sin embargo, el autor se ocupó de este género y legó a la literatura costarricense trece relatos de tres orientaciones diferentes. Los primeros tres fueron publicados en la prensa entre 1901 y 1905, los restantes se incluyeron en el poemario Nómadas (1905). De ellos, únicamente "Incidentes de don Pancracio" (1901) fue dado a conocer con la firma de Chavarría; todos los demás se editaron bajo el nombre de la primera esposa del autor: Rosa Corrales de Chavarría. ${ }^{1}$

La primera orientación narrativa tiene que ver con textos de carácter costumbrista. En esta tendencia se ubican: "Incidentes de

\footnotetext{
${ }^{1}$ Este hecho obedeció al interés del escritor por proyectar su obra, lo cual creyó que repercutiría mejor si, en común acuerdo con su esposa, ella asumía la función autoral. La decisión funcionó bastante bien hasta 1905 (cuando el esposo reclamó la autoría), porque Rosa Corrales se convirtió en una reconocida escritora tanto en Costa Rica como en el exterior. Véanse los detalles de este caso en Rodríguez Cascante 2013: 6-46.
} 
don Pancracio (1901), "Serenata campestre" (1903) y "Dormido" (1905). La segunda tendencia agrupa relatos con referencias intertextuales clásicas, todos, menos "Omar, el pescador" (1902) publicados en Nómadas: "Venganza de Isis", "Triunfo de Cleopatra" y "Artémida". La tercera orientación consiste en relecturas bíblicas, también textos de Nómadas: "Susana", "El bautista", "Magdalena", "El buen ladrón", "En Gethsemaní" y "En el tabor".

En este artículo se estudian estos tres caminos de la narrativa escrita por Lisímaco Chavarría. En primer lugar, se presta atención a los relatos costumbristas y a sus preocupaciones estéticas e ideológicas, para, posteriormente, analizar las representaciones orientalistas del segundo grupo de relatos. En este nivel, se da cuenta de las fuentes de tales discursos y de sus reelaboraciones de personajes y acontecimientos históricos. Finalmente, se consideran los cuentos que efectúan relecturas de pasajes y personajes bíblicos, para enfatizar dos vertientes: una que se distancia del texto original para amplificar, mediante la erotización, la imagen de la mujer; y otra que se apega más al modelo con el fin de insistir en el paradigma moral del texto sagrado.

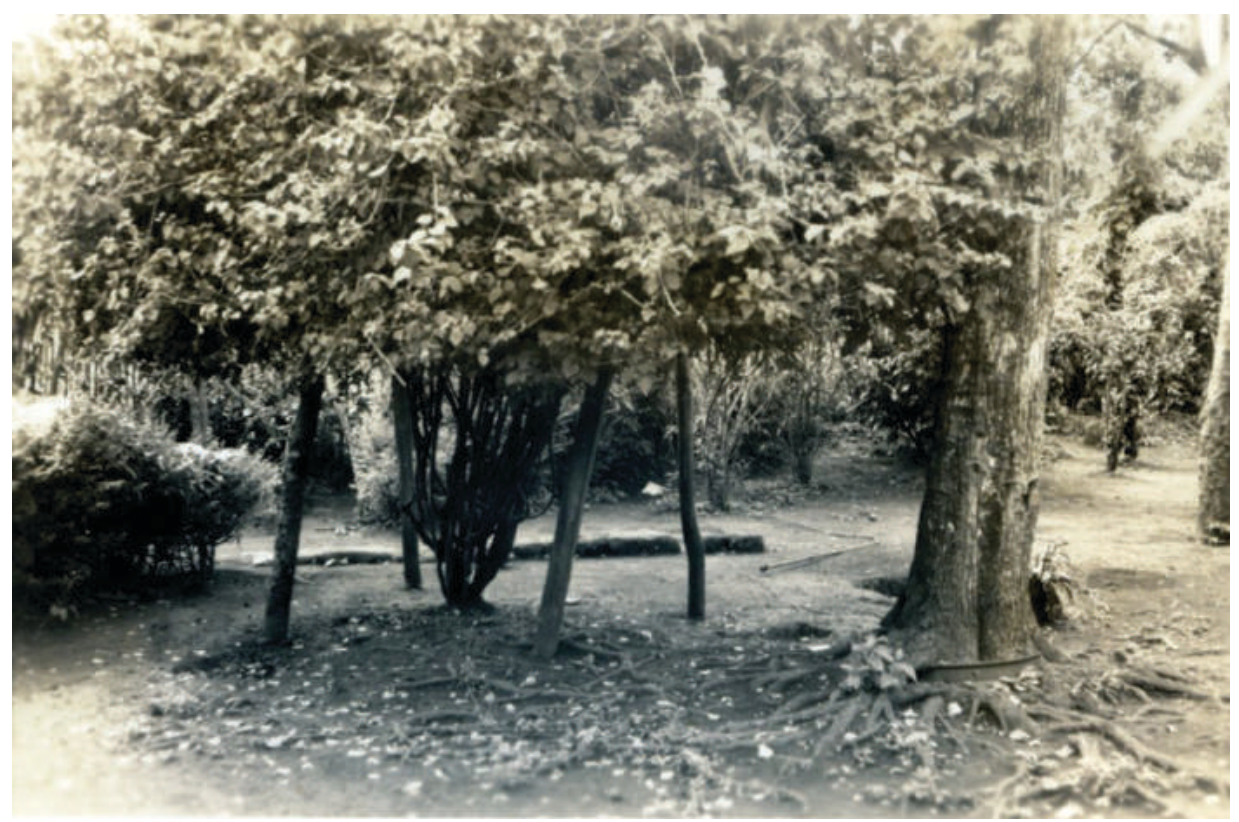

Foto 2: Solar donde creció Lisímaco Chavarría, el cual se encontraba ubicado detrás de la casa paterna. En: María Isabel Araya Coronado. Biografía y obra de Lisímaco Chavarría Palma. Tesis. Escuela de Letras y Filosofía. Universidad de Costa Rica, 1950, páqina 27. 


\section{LOS RELATOS COSTUMBRISTAS}

Tanto en España como en Hispanoamérica, el costumbrismo se manifestó en distintos géneros discursivos: novelas, cuentos, cuadros de costumbres, artículos periodísticos, poesías, etc, todos ellos marcados por un común denominador: la delimitación de una realidad próxima valorada muchas veces por medio de una moralidad codificada por las tradiciones decimonónicas ${ }^{2}$.

Por otra parte, el costumbrismo concibe de manera referencial la verosimilitud, por ello estima que sus distintos niveles de representación producen textos, antes que ficticios, documentales. Desde esta perspectiva, como sostiene Isabel Román (1988: 171), el cuadro de costumbres es entendido por sus autores en un sentido fotográfico o pictórico, en donde el escritor aparece como el intermediario entre el objeto y el receptor. Por ello, el autor observa y captura elementos del entorno para trasladarlos a la realidad de la manera más fiel posible. ${ }^{3}$

"Incidentes de don Pancracio" es un estilizado y humorístico relato costumbrista que reelabora la tradición de la bruja costarricense, motivo internacional que Chavarría desarrolla mediante la construcción muy verosímil de un adulto mayor, don Pancracio, quien es ferviente creyente en los fenómenos del más allá y en sus manifestaciones. Tanto es así que cualquier acontecimiento que no coincida con el más elemental sentido común, él lo interpreta como producto del más allá. Su dimensión supersticiosa lo mantiene constantemente en estado nervioso: "Una hoja que rueda impelida por el viento, es para él una bruja, una rama que balancee la brisa durante la noche, es un aparecido de la otra vida

\footnotetext{
${ }^{2}$ Como indica Julián Moreiro, bajo la categoría de costumbrismo "se incluyen una serie de textos literarios, independientes o insertos en obras de mayor extensión, que describen escenas, ambientes o personajes de la realidad circundante. Con frecuencia traslucen una intención filosófica o moral, muchas veces destinada a la censura de conductas y actitudes." (2002: 11).

3 La realidad construida por los costumbristas es una representación tipificada e inmovilizada. Dice, al respecto, Román: "Y esto no sólo por lo que respecta a los tipos, sino también a las escenas. Los primeros son descripciones de personajes estáticos y tipificados, genéricos, representativos de un determinado grupo o clase, y cuya individualidad es nula. Deben gran parte de su éxito, además de a la aparición de la fotografía, a las 'fisiologías' que surgen en Francia a partir de 1840. Los caracteres están deshumanizados, son unas abstracciones cuyas realizaciones concretas no siempre responden en la realidad a su modelo." (1988: 173).
} 
que le sale en acecho" (2013 II: 356) ${ }^{4}$. A tal extremo llegan sus creencias sobrenaturales que su vida está marcada por ellas: cree en el mal agüero del ópalo, del número trece, del ruido del grillo y las palomas.

Su superstición se convierte en paranoia cuando determina que ña Timotea, su vecina, es una bruja que quiere hacerle daño, puesto que en unas fiestas de la Merced, le majó un callo. Su reacción es interpretar todos sus acontecimientos cotidianos como situaciones extrañas provocadas por la brujería. Ante esto, busca a ña Timotea y la increpa, solicitándole que deje de atormentarlo.

Una noche escuchó ruidos y salió a investigar, descubrió una lechuza, en quien reconoció a la bruja convertida en el animal, por esto preparó un fuego y quemó a la lechuza, lo cual le provocó una inmensa tranquilidad, pero al otro día al ver salir a ña Timotea de su casa, le dio un ataque epiléptico y fue conducido a su lecho.

Este relato muestra el interés de Chavarría por textualizar las tradiciones costarricenses de su época, universo simbólico que se mantiene como parte de los marcadores identitarios de la Costa Rica de finales del siglo XIX y de principios del XX. Lo hace desde una estrategia retórica que procura alcanzar la objetividad, por ello el inicio del texto indica: "Parece mentira, pero es verdad" (II: 356), enunciado que reclama un pacto de verosimilitud con el lector, al mismo tiempo que oculta la subjetividad de un narrador que domina de manera absoluta tanto los acontecimientos como las subjetividades de sus personajes. Estamos en presencia de un narrador fuerte, con una presencia permanente en el texto, ejercicio característico del código costumbrista, donde todos los acontecimientos están marcados por la óptica de esta figura omnisciente. De esta manera, la realidad enunciada es una selección de ese punto de vista, tan cercano al género periodístico donde el costumbrismo desarrolló, bajo las mismas reglas, los cuadros de costumbres. ${ }^{5}$

\footnotetext{
${ }^{4}$ En adelante, cito únicamente con la indicación del tomo correspondiente y el número de página. Todas las referencias remiten a las Obras completas de Chavarría (dos tomos) apuntadas en la bibliografía.

5 Para Enrique Pupo Walker, esta íntima relación entre la textualidad y la realidad circundante produjo lo que él califica de agotamiento histórico del género: "En gran medida el desgaste imaginativo de la narración costumbrista radica, pues, en que el texto asume como orden primigenio la realidad exterior, y en que el discurso se constituye como signo de la misma. Desprovistos de otras posibilidades, esas estampas descriptivas se aferraron asiduamente al dato pintoresco y a los ripios de la historia. Es más que nada por esas razones que la narración costumbrista aparece hoy como escritura envejecida que evoca la imagen borrosa del daguerrotipo." (1978: 11). Sin embargo, más que ver el costumbrismo como un género agotado, habría que considerar sus propuestas
} 
Este reclamo de verosimilitud está justificado en el relato de Chavarría mediante el llamado a la creencia comunal y su expresión anónima, es decir al ocultamiento de la elaboración individual, por parte del narrador, de los acontecimientos que enuncia y su atribución a una voz colectiva y sin autoría: "Cuentan que un día salió a cazar" (II: 356), "Cuentan que en su chaleco encontraron un poco de mostaza bendita" (II: 358). Sin embargo, esta estrategia no impide esa necesidad del costumbrismo de acercar a su lector a los hechos relatados. Chavarría, luego de mencionar algunos incidentes ocurridos al protagonista, apela a su enunciatario con el fin de hacerlo partícipe de la fábula referida y con ello reforzar sus condiciones de verosimilitud: "Desde este incidente, nuestro amigo en cuestión, oyó golpecitos en su casa...." (II: 357). De esta manera, el relato elimina la distancia entre el lector y los acontecimientos y busca un efecto de realidad que trascienda la ficción.

A diferencia de este registro sobre la superstición, "Serenata campestre" aborda otra de las tradiciones fundamentales que determinaron la construcción simbólica de la identidad costarricense de la época, la cual subsiste con modificaciones hoy día: la costumbre de llevar serenatas a las jóvenes pretendidas. Este relato se articula mediante el empleo diferenciado tanto del código modernista como del costumbrista. En relación con el primero, el texto presenta una estilizada descripción introductoria donde abunda en los detalles de la geografía regional en la

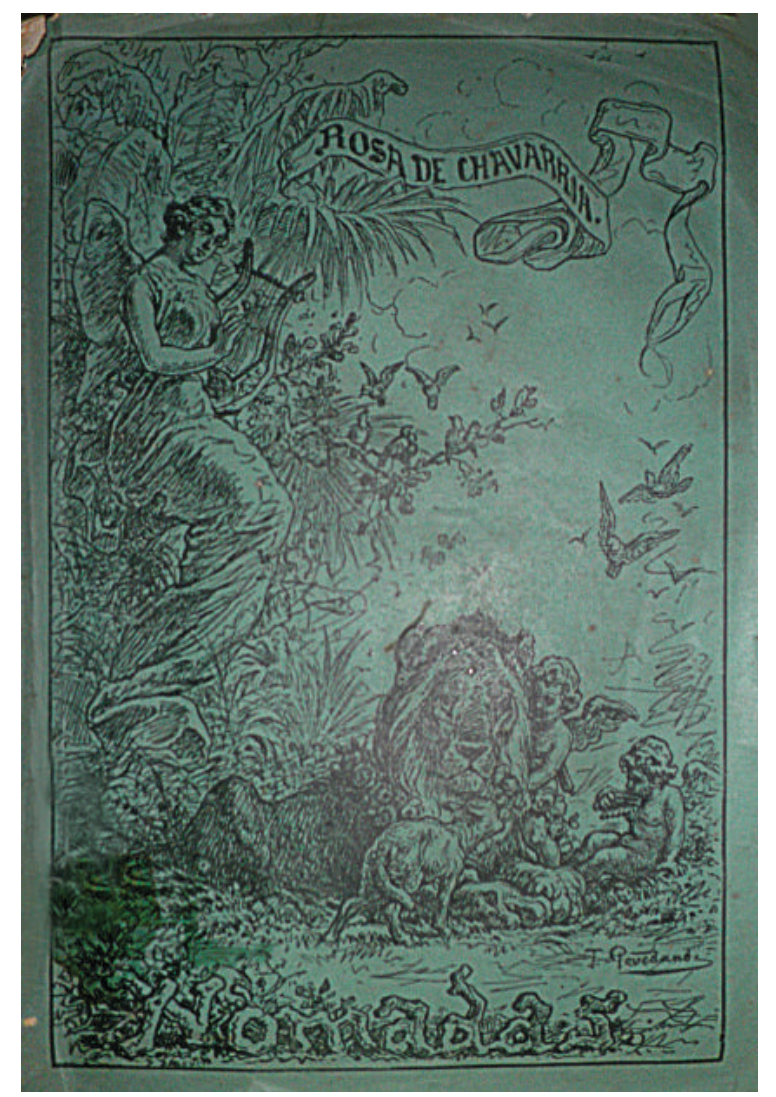

Foto 3: Portada de Nómadas, obra en la cual se publicaron varios de sus cuentos, basada en el grabado que para tal efecto realizó Tomás Povedano, amigo de Lisímaco. En: Lisímaco Chavarría. [Rosa de Chavarría] Nómadas. San José: Imprenta Nacional, 1905. Sin número de páginas.

identitarias contextuales, espacios donde podemos leer hoy esfuerzos valiosos por fijar momentos de la memoria histórica. 
cual ocurre el acontecimiento musical que textualiza: "Sobre las copas de los ceibos de los bosques, tiende la luna su crencha argentada; los grillos entonan sus cantares monótonos y metálicos, las luciérnagas brillan como pupilas de fuego y uno que otro perro ladra desde el portal de las viviendas del caserío" (II: 363).

Este decorado escenario modernista, desarrollado mediante la estrategia retórica de la figura Ut pictura poiesis donde "la poétique concerne au premier chef la peinture" (Larue 1998: 2), se convierte en ejercicio propedéutico que anuncia una tradición presentada por medio del descubrimiento pausado que el enunciador ofrece a su lector. Luego de mostrar, sin detalles, dos siluetas que parecen espectros blancos, pregunta: "¿A dónde van a esa hora esos dos hombres? No se puede adivinar; el barrio duerme, las callejuelas están desiertas..." (II: 363). Tal escenario pictórico tenebroso le permite introducir el interés de estos dos sujetos de ofrecer un regalo musical a una muchacha. El relato insiste en enumerar la ceremonia de preparación de la serenata con todos sus detalles: cómo apoya uno la guitarra en su pierna, cómo afina el instrumento, cómo prueba múltiples sonidos hasta que, junto a una rústica morada, se escucha la canción, cuya letra el texto ofrece de manera completa. Un fragmento de esa inserción textual es el siguiente:

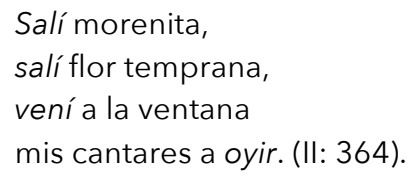

Como se aprecia, el relato ha dado paso a la voz del otro, a uno de los dos campesinos presentados al inicio del texto, pero esa traslación de la voz narrativa implica también un distanciamiento lingüístico marcado tipográficamente por la itálica, con lo cual el autor afirma la presencia del voseo campesino, propio de los registros populares de la Costa Rica de principios del siglo XX. Se evidencia, por esta vía del código lingüístico, uno de los requerimientos del costumbrismo costarricense: la interrelación entre un narrador que acude al registro culto y que cede la palabra al código popular en la voz de los campesinos que representa discursivamente.

Esta doble vía discursiva, frecuentemente utilizada por la narrativa costarricense de finales del siglo XIX y principios del XX, generó un conjunto de textos híbridos en los cuales los lenguajes campesinos se mezclaron con los códigos letrados canonizados por los 
movimientos literarios dominantes del contexto. ${ }^{6}$ Este es el caso de la escritura lírica y narrativa de Lisímaco Chavarría, puesto que el interés de la poética planteada por el autor radica en asumir las tradiciones y sus lenguajes para ponerlos a dialogar con los registros eruditos del romanticismo y el modernismo.

Luego de esta presentación, in extenso, de la voz popular manifestada en la letra de la canción, el enunciador retorna al lenguaje erudito del modernismo: "La última palabra del trovador y el postrer acorde de su guitarra..." (II: 364), para mostrar la marcha de los jóvenes músicos hacia las mismas serranías por las que llegaron. Sin embargo, el texto no concluye allí, termina en un ejercicio híbrido de combinación entre ambos códigos, el costumbrista y el modernista, dando cuenta de que la asunción de los cánones letrados por parte de Chavarría, implican un reconocimiento y apropiación del criollismo:

Pocos momentos después, los gallos de la vecindad anunciaron la aurora con sus cantos; los yigüirros la festejaron con armoniosos trinos, las cabañas rústicas del caserío abrían sus puertas y de sus techos se levantaban inmensas espirales de humo. (II: 364).

Como se observa en lo indicado hasta el momento, Lisímaco Chavarría textualiza un costumbrismo estilizado y por medio de esta codificación incorpora ese esfuerzo por "captar el habla de los personajes" (Sandoval 1992: 11) y construir un "retrato, testimonio para la posteridad de un pueblo original que merecía ser retratado" (Picado 1991: 222). Todo ello corresponde con el anhelo verosimilizante del costumbrismo, cuya apuesta consiste en captar la realidad de un momento histórico, "buscando lo que en él prevalece de tradicional." (Sandoval 1992: 10).

Es de gran interés en el relato costumbrista la fijación de determinados tipos sociales, especialmente los populares (Rubio Cremades 1983: 464). Refiriéndose a la construcción de estos sujetos en el costumbrismo, afirma Cuvardic García que su "función es describir la profesión o función social de un personaje"

\footnotetext{
${ }^{6}$ Sobre el costumbrismo costarricense, señala Álvaro Quesada: "Reconocemos como costumbrista cierto tipo de discurso literario -al que Fernández Guardia calificó durante la polémica de 'género concho'- que se caracteriza por recoger elementos formales y lingüísticos de otros discursos 'marginales', que no cumplían funciones estrictamente 'literarias' y 'artísticas', sino más bien periodísticas, humorísticas o folclóricas. Dentro del nuevo sistema literario, esos elementos integran una estructura distinta y producen un nuevo discurso -criollo e híbrido-, que expresa una original visión del mundo y que pasa a cumplir, dentro del contexto histórico-cultural costarricense, funciones propiamente literarias. (1995: 159).
} 
(2008: 37). Sin embargo, como ha señalado Luis María Brox, esta constitución implica una descripción superficial, en donde "el lector se pueda reconocer fácilmente y en que además ese reconocimiento no sea problemático, no ponga en cuestión la existencia misma de ese tipo escogido." (1975: 104). Como tipo social, los personajes del costumbrismo necesitan esa fijeza en su representación, no son pues personajes complejos en los cuales el autor muestre contradicciones psicológicas 0 profundos problemas existenciales. Antes bien, son sujetos como don Pancracio, ña Timotea o los trovadores anónimos que recuperan la tradición musical que Chavarría estima importante de fijar literariamente, en tanto muestra de un referente identitario de la Costa Rica de su época.

Esta construcción de tipos humanos está claramente presente en el último relato costumbrista de Lisímaco Chavarría, el breve texto "Dormido", que forma parte del poemario Nómadas (1905). En él, Marta, madre de un pequeño niño enfermo de bronquitis, al levantarse un día lo encuentra profundamente dormido, lo cual la alegra mucho debido a que ya no se queja como lo hacía el día anterior. Unos momentos después llega el médico y la madre, contenta, le dice que está mejor y que ahora duerme. El galeno ingresa al cuarto del pequeño y determina que ha muerto; ante esta noticia terrible, la madre enloquece:

\footnotetext{
La madre se acercó a la cuna, le miró con avidez, le dio un ósculo en la frente y soltó una carcajada horrible y larga...muy larga...

De súbito la pobre Marta se había tornado loca. Desde entonces se oye repetir a aquella madre: -¡No hagan ruido porque se despierta el niño! (I: 221).
}

Esta tipificación de una madre que deviene demente ante la muerte del hijo es planteada mediante una breve caracterización que no profundiza ni en la subjetividad de los personajes ni en la descripción de sus condiciones de vida o motivos que provocaron los hechos; interesa al autor únicamente pintar un cuadro de la vida campesina donde una sencilla enfermedad era sinónimo de muerte ante las deplorables condiciones sanitarias de esa población en la Costa Rica de principios del siglo XX. Por ello, el relato se convierte en ese cuadro que tiene vínculos intertextuales con el conocido poema costumbrista de Aquileo Echeverría "La vela de un angelito" (1980: 29-33), donde se elabora, igualmente, la muerte de un niño en un contexto campesino, aunque este texto mantiene una dimensión festiva del evento trágico. 
Ese propósito del costumbrismo de procurar ser una reproducción de la realidad que merece ser registrada como fuente de la tradición de un contexto, se relaciona estrechamente con los proyectos de construcción nacional implementados en la América Latina de la época de Lisímaco Chavarría. El esfuerzo por representar tipos sociales asociados con costumbres raigales marcadoras de identidad tradicional es indudablemente un trabajo intelectual que coadyuvó en la elaboración de los imaginarios culturales de finales del siglo XIX y principios del XX, puesto que como sostiene José Escobar, "Las costumbres cambian a medida que se transforma la sociedad en el proceso histórico de un país y expresan la condición moral de esa sociedad." (1983: 162). Por ello, para los escritores costumbristas resultaba fundamental efectuar esos registros memorialísticos, en conexión tanto con la tradición como con el tránsito que esas sociedades aspiraban realizar hacia la modernización.

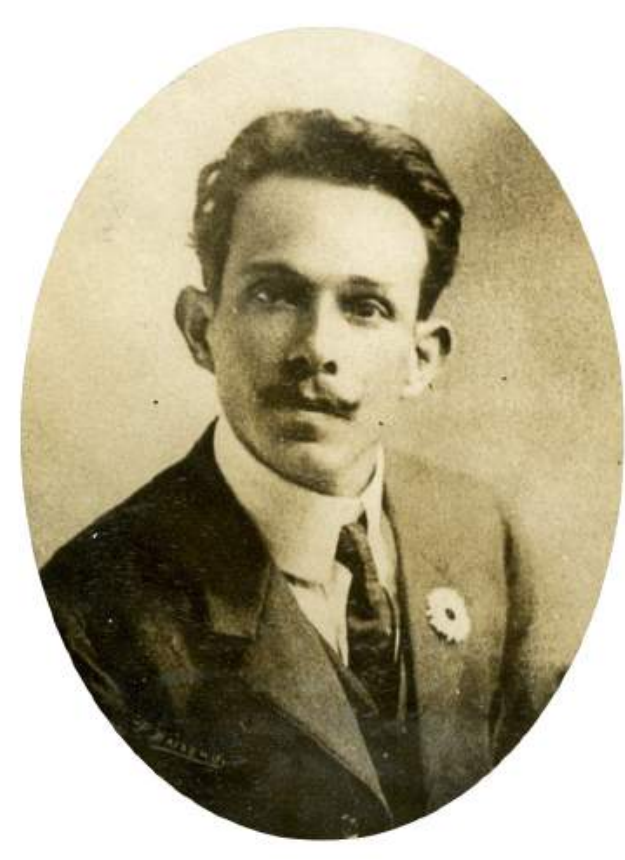

Foto 4: Fotografía tomada cuando el autor ganó los Juegos Florales de 1909. En: María Isabel Araya Coronado. Biografía y obra de Lisímaco Chavarría Palma. Tesis. Escuela de Letras y Filosofía. Universidad de Costa Rica, 1950, sin número de página.
Dice Susan Kirpatrick que "the costumbrismo was necessarily an ideological manifestation of the transition to modern, burgeois society." (1978: 31). Cabe recordar que el costumbrismo latinoamericano se produce en un contexto decimonónico que tenía en su mira, además de la constitución de nuevas naciones los procesos de modernidad, el nacimiento de la prensa y la recepción del costumbrismo español (Lasarte 1997: 176). Esta coyuntura instaura la necesidad de construir los imaginarios nacionales a partir de la fijación de programas sociales que permitieran desarrollar una imagen del ciudadano con base en paradigmas tradicionales de los cuales partir, y fundamentadas en ellos las personas pudieran compararse y afirmarlos en tanto modelos 
propios de sus orígenes. Esta es la tarea que el costumbrismo procuró cumplir de la mejor manera en las nacientes literaturas del subcontinente latinoamericano, y en el caso costarricense, Lisímaco Chavarría se unió en este proyecto a las grandes figuras del costumbrismo nacional, como Manuel González Zeledón (1864-1936), Aquileo Echeverría (1866-1909) y los fundadores de la crónica histórica: Manuel Argüello Mora (1834-1902) y Manuel de Jesús Jiménez (1854-1916).

\section{LA NARRACIÓN DEL ORIENTE}

La segunda tendencia agrupa cuatro textos con manifiestas representaciones del Oriente. Se trata de los relatos "Omar, el pescador", Venganza de Isis", "Triunfo de Cleopatra" y "Artémida". Refiriéndose al modernismo español, sostiene Carvajal Milena que existen tres fuentes de inspiración en dicho movimiento: el mundo clásico grecolatino, Francia y España. (2004: 164). En el caso latinoamericano, falta agregar una fuente imprescindible: el Oriente, universo colmado de los más abundantes imaginarios sobre la otredad, cuyas raíces, como sostiene Silvia Nagy, se remontan al modernismo y más allá. (2008: 14).

Este orientalismo de los autores modernistas no constituye un conjunto homogéneo de discursos, sino, por el contrario, una diversidad textual que pasa tanto por aquel imaginario que procura regular la otredad para exorcizarla de sus peligros, según el argumento de Edward Said ${ }^{7}$, como por los sinceros intentos de asumirla en tanto forma de rechazo de la racionalidad occidental y la consecuente búsqueda de nuevos caminos de comprensión del ser humano; ejemplo de esta orientación es gran parte de la obra del escritor salvadoreño Salvador Salazar Arrué (conocido como Salarrué) $)^{8}$.

\footnotetext{
${ }^{7}$ Refiriéndose al Islam, dice el pensador en su difundida obra Orientalismo: "Quiero decir con esto que las ideas sobre el Islam que circulaban eran necesariamente una versión devaluada del sólido peligro que simbolizaba para Europa. Como los sarracenos de Walter Scott, la representación que Europa hacía de los musulmanes, otomanos o árabes era siempre una manera de controlar a un Oriente temible, y lo mismo se puede decir hasta cierto punto de los métodos de los orientalistas eruditos contemporáneos, cuyo tema de estudio no es el propio Oriente, sino Oriente convertido en algo conocido y, por tanto, menos temible para los lectores occidentales." (1990: 86).

${ }^{8}$ En un importante estudio sobre la obra del escritor, indica Ricardo Roque Baldovinos: "Manifestaciones de misticismo oriental como la teosofía son, no debemos olvidarlo, creaciones occidentales, es decir incursiones en el pensamiento oriental animadas por la mala conciencia de Occidente. Estas ofrecen un atractivo grande sobre ciertos sectores porque dan respuestas atractivas a problemas acuciantes. En primer lugar, las corrientes místicas orientalistas plantean una crítica de raíz al eurocentrismo y la vanidad occidental
} 
En el caso de la narrativa de Lisímaco Chavarría, la representación del Oriente no implica la búsqueda de una fuente de pensamiento alternativo para entender la realidad ni una negación de los procesos de modernización que impulsaban los proyectos liberales costarricenses; tampoco una necesidad de mostrar algún grado de degeneración de las sociedades orientales, sino que su inmersión orientalista corresponde más bien a un empleo erudito de carácter intertextual que le sirve de escenario exótico para ubicar sus tramas narrativas. Si, como sostiene Aníbal González, el modernismo fue "la apropiación y reorganización parcial de la Biblioteca de la cultura europea por parte de Hispanoamérica" (2006: 98), para Chavarría este acervo se complementó con la Biblioteca Oriental, ya que acudió insistentemente a ella para ampliar sus escenarios literarios.

En el cuento "Omar, el pescador", los afanes orientalistas se presentan desde la dedicatoria del mismo para su madre: "Cuento oriental. Para doña Teresa Palma de Chavarría". Se trata del relato de un amor imposible: el joven y pobre pescador de la ciudad de Damghán, que pertenece a la provincia persa de Semnan, Omar, está enamorado, sin que ella tenga idea, de la princesa Sadí. Los padres del joven, ambos ancianos, enfermos y dependientes, también ignoran los sentimientos de su hijo. Omar se dedica a la pesca y vende sus productos en el mercado de otra ciudad persa: Asterabab, donde se entera de que el producto de su trabajo es dirigido a la fiesta del Monarca, ya que su hija Sadí se casa con el príncipe Nabor Tabrís, de la importante ciudad de Ispahán. Al enterarse de la noticia, el pescador decide introducirse en el palacio y logra llegar a la habitación donde Sadí se prepara para su boda.

Una vez allí, se presenta ante la princesa y le confiesa su amor, le expresa que nadie la ama como él y que hace más de un año solo vive para ella. Asimismo, le propone que se escapen juntos porque

de arrogarse la exclusividad del espíritu de la humanidad. Esto tiene una importancia todavía mayor en al periferia de Occidente, porque lleva consigo la reivindicación de otras tradiciones culturales, algunas de ellas marginadas por la hegemonía del modelo europeo como puede ser el caso de grandes tradiciones culturales como las de la India y la China, otras virtualmente soterradas bajo los escombros de una conquista etnocida como es el caso de las culturas americanas precolombinas. En este sentido, creo que no se ha insistido lo suficiente en el papel que juega el orientalismo en la resurrección de las culturas precolombinas americanas. La vida y obra de Salarrué abunda en testimonio de ello. En su vida Salarrué busca entrar en contacto con la religiosidad chamánica sobreviviente en la zona náwat de El Salvador. En su obra, tenemos el ejemplo de O'Yarkandal, donde Salarrué inventa una mitología que fusiona referencias a los libros sacros del hinduísmo con referencias al Popol Vuh." (1997: 35). 
ella nunca será la esposa de Nabor Tabrís. La muchacha, ofendida y asustada, golpea con su sandalia al joven que se encuentra arrodillado. Omar reacciona sacando un puñal e hiriendo de muerte a la princesa. Al final del relato, los ancianos padres del joven pescador encuentran su cadáver en la playa, víctima del suicidio.

La descripción del espacio narrativo presente en el relato muestra ese imaginario libresco (Chavarría salió del país únicamente una vez: a Guatemala en 1911) que alimentaba las ficciones sobre el Oriente, el cual era visto en tanto lugar exótico dominado por noblezas llenas de ostentación, lujo y riqueza, frente a un pueblo que las idolatraba.

Esta enumeración del lujo exótico coincide con las "japonerías" que estudia Roque Baldovinos en los escritores modernistas centroamericanos Enrique Gómez Carrillo y Arturo Ambrogi, artefactos de un escenario orientalista que se constituye como emblema de una experiencia estética. "Nos referimos -dice el estudioso- a la experiencia implícita en la adquisición y contemplación de un artefacto de lujo, cuyo significado cultural originario, al ser completamente ajeno a las referencias del espectador, se vuelve irrelevante. La japonería es una fascinación por la superficie de artefactos despojados de su sentido." (2009: 175).

Esta separación del significado contextual-cultural ocurre en este relato de Chavarría tanto respecto a los objetos y su exotización, como a los seres humanos, especialmente con la figura de la princesa, sesgo propio de la representación orientalista de la figura femenina. ${ }^{9}$ Obsérvese el funcionamiento de ese imaginario que deslumbró a los escritores modernistas centroamericanos en esos dos niveles de descripción, la hija del monarca y sus propiedades personales:

La regia cámara de la princesa Sadí se hallaba, como nunca, deslumbrante y abrillantada con lumbre roja; ricos divanes de damasco, jarrones del Japón, biombos chinescos y tapices finísimos de Persia, adornaban aquella estancia.

\footnotetext{
9 Refiriéndose a la representación de la feminidad japonesa que desarrolla Gómez Carrillo, dice Roque Baldovinos: "La otra expresión por excelencia del espíritu artístico espontáneo del Japón que Gómez Carrillo encuentra es la musmé, la mujer japonesa. Es precisamente la visión de una de estas musmés, la que puede restaurar el aura del exotismo oriental que amenazaba disiparse al primer encuentro con el Tokio europeizado de los ferrocarriles. [...] Al ser el Japón el locus del exotismo, es un espacio que se emblematiza en el cuerpo femenino. El cuerpo femenino se convierte así en el objeto desde el que se construye la subjetividad masculina del viajero." (2009: 178-179).
} 


\begin{abstract}
Allí está ella, la futura esposa de Nabor Tabrís.
Una bata de seda color de rosa cubre su talle escultural, brazaletes de oro con admirables incrustaciones de piedras preciosas ciñen aquellos brazos mórbidos, al verla se confunde con las diosas que decoran los tapices de su estancia, o con las estatuas que se elevan sobre plintos de oro en su contorno; piensa quizás, en su ventura tan cercana. (II: 360-361).
\end{abstract}

De Persia, el espacio narrativo de Chavarría se traslada a Egipto en el cuento "Venganza de Isis", en el cual se representa la travesía de un barco negrero que viene del norte de África, cargado de tristes esclavos negros recién atrapados por un malvado capitán cuyas pretensiones es obtener una buena suma de dinero producto de la venta de dichas personas. Entre ellas, el despiadado marino logró atrapar en Alejandría a una hermosa joven blanca, fiel devota de Isis, a quien se encomienda.

El texto describe los lujuriosos deseos del capitán, quien se decide a violar a la joven, en un contraste barroco entre la luz y la oscuridad, donde la bella egipcia rememora con la nostalgia de alguien que nunca regresará a su patria:

\footnotetext{
Los infieles prisioneros tendidos sobre el pavimento de los calabozos, se habían dormido de fatiga; solo velaba en el suyo la bella egipcia, velaba pensando en su patria, en su familia, en los camellos, en las Pirámides y veía esfumarse en sus recuerdos aquellas tardes áureas en que contemplaba embebecida las misteriosas y mudas esfinges, y la silueta gentil del mancebo que en las riberas del Nilo, la víspera del día que la arrancaron de su patria, la juró amor eterno prometiendo hacerla su esposa. (I: 219).
}

Al final del relato, luego de su violación, la joven pide a Isis que castigue la crueldad del capitán, e inmediatamente estalla una tormenta y un rayo cae en la cabeza del marino carbonizándolo. Cuando concluye el fenómeno, los marineros encuentran el cadáver de la joven, quien ante la deshonra, decide ahorcarse.

Oriente es un lugar imaginario, un espacio libresco antes que una geografía histórica, en donde prima el reino del espíritu. Si, como señalan Chevalier y Gheerbrant, en el imaginario simbólico occidental, Oriente se opone al Occidente como la espiritualidad al materialismo (1999: 710), en estos relatos de Chavarría el interés se dirige a mostrar cómo en esos lejanos y fabulosos países existen seres humanos ideales que dan su vida por el amor ideal. Son textos donde la hiperbolización del ámbito sentimental domina los paisajes y sus abundantes geografías. Sus personajes, ya sean masculinos como Omar, o femeninos como la joven adoradora de 
Isis, se constituyen en símbolos de la pureza espiritual del amor, valor que los hace renunciar a la vida.

En los relatos "Triunfo de Cleopatra" y "Artémida", Chavarría une esta representación del Oriente con las fuentes grecorromanas, discursos, estos últimos, fundamentales en las articulaciones intertextuales modernistas, aspectos presentes, por supuesto, en la narrativa del gran modelo literario que era, en el período de producción textual del escritor costarricense, la obra de Rubén Darío $^{10}$. Chavarría asume este paradigma con el fin de inscribirse en la legitimación de los marcos culturales de su momento histórico. Esto explica su asunción del romanticismo y del modernismo con sus variadas fuentes y orientaciones.

El primero de los cuentos se ocupa de la recreación del encuentro y enamoramiento de Marco Antonio de la reina Cleopatra VII en el año 41 a.C. El texto se ubica en Alejandría, justo en el momento en que Cleopatra espera a Marco Antonio, quien viene a hacerla prisionera por órdenes del César. El relato, igual que los demás de esta sección, ahonda en la representación exótica del Oriente y de la mujer, concebida como la belleza extranjera que asombra al escritor occidental por su sensualidad y sus lujos:

\begin{abstract}
Solo la bella Cleopatra, la seductora reina, velaba en su lecho de marfil que sostenían cuatro dragones de oro, y cubría un dosel de ormesí de Jonia. Los cobertores la cubrían hasta la cintura, dejando ver su busto escultural, cuyas curvas resaltaban al través de una túnica de seda de Cos. Adornábanle una serpiente de oro incrustada de esmeraldas el cuello; brazaletes de ágatas y topacios los brazos. (I: 222).
\end{abstract}

Este imaginario sobre la otredad ofrece un estilizado despliegue del lenguaje modernista, mediante el cual Chavarría describe la perfección física de ambos personajes, lo que permite, en el relato, la plena identificación de los dos y el nacimiento de un amor instantáneo que provoca el cambio repentino de planes por parte del militar romano: abandona su misión y decide rendirse a los pies de la reina de Egipto. Ambos, conocedores del peligro que

\footnotetext{
${ }^{10}$ Refiriéndose a la novela inconclusa de Darío El hombre de oro, dice Roberto Fuertes Manjón: "Como en otras muchas novelas modernistas, la acción se ambienta en el mundo clásico, concretamente en la época de Tiberio. Esta obra es una muestra de la prosa novelística modernista en toda su pureza, caracterizándose por la riqueza léxica, abundancia de cultismos, preocupación por lo sensorial, riqueza de imágenes y la recreación del ambiente clásico." (1997: 115). Cabe destacar que Lisímaco Chavarría escribió entre 1896 y 1913.
} 
entraña esta decisión, deciden disfrutar su amor a la espera de que Octavio envíe otro embajador a Alejandría.

En "Artémida" se relata nuevamente otra historia de amor: la de Lisandro, un militar macedonio que participó activamente en la Batalla de Queronea, quien está enamorado de Artémida, hija de un caudillo ateniense. Para no ser descubiertos debido a la rivalidad entre atenienses y macedonios, el enamorado visita a la joven ocultándose en el palacio del padre de Artémida. Sin embargo, pese a sus cuidados, una noche es atrapado y acusado de traidor del pueblo macedonio, por lo cual lo ejecutan. Artémida pide audiencia al Consejo de Guerra de Macedonia y explica que Lisandro nunca fue un traidor porque la visitaba a ella y nunca a Panecio, su padre, el gobernador de Atenas. Luego de su confesión, la joven enloquece y huye por las llanuras de Beocia.

La espiritualidad amorosa, ya vista en la construcción de personajes femeninos y masculinos, en este texto, plantea que dicho sentimiento trasciende las fronteras geográficas y culturales, así como asume el tópico del sacrificio del inocente, quien sucumbe ante un conjunto de circunstancias azarosas que delinean un destino trágico para el personaje. Esta confabulación de la existencia está presente en las cuatro historias de recorrido orientalista desarrolladas por Chavarría.

\section{LAS RELECTURAS BÍBLICAS}

Distanciándose de estas recreaciones históricas del mundo antiguo, un conjunto de seis relatos efectúan relecturas bíblicas, fenómeno altamente productivo en la historia literaria internacional y en la del movimiento modernista ${ }^{11}$. Se trata de un grupo de textos que Chavarría reunió en una sección de su libro Nómadas titulada "Fantasías bíblicas". Estamos en presencia de ejercicios narrativos ficticios fundamentados en los textos sagrados.

El primero de ellos es "Susana", que reelabora la historia de este personaje contada en el Libro de Daniel, en donde Susana, la esposa de Joaquín, es acosada por dos jueces innominados en el relato bíblico, y ante su negativa deciden acusarla de adulterio,

\footnotetext{
11 Sobre la presencia de temas bíblicos en la literatura, dice con razón, por ejemplo, Enrique Banús, que habría que hablar de "superabundancia", y que "No sólo personajes tienen una importante vida literaria, también algunos de los libros bíblicos resonarán a lo largo de la historia de la literatura." (2005: 98).
} 
ante lo cual Daniel intercede y demuestra la falsedad de los dos ancianos; con ello salva a Susana y castiga a los falsos jueces ${ }^{12}$.

La relectura de este texto bíblico efectuada por Chavarría se caracteriza por desplazar la parquedad del texto sagrado respecto a los atributos de Susana, y enfatizar en ellos promoviendo características eróticas en el personaje, lo que transgrede y va más allá de la intencionalidad del pasaje bíblico, es decir la mostración y exaltación de la castidad de dicha heroína. Más que este atributo, el cuento de Chavarría construye un discurso erótico que echa

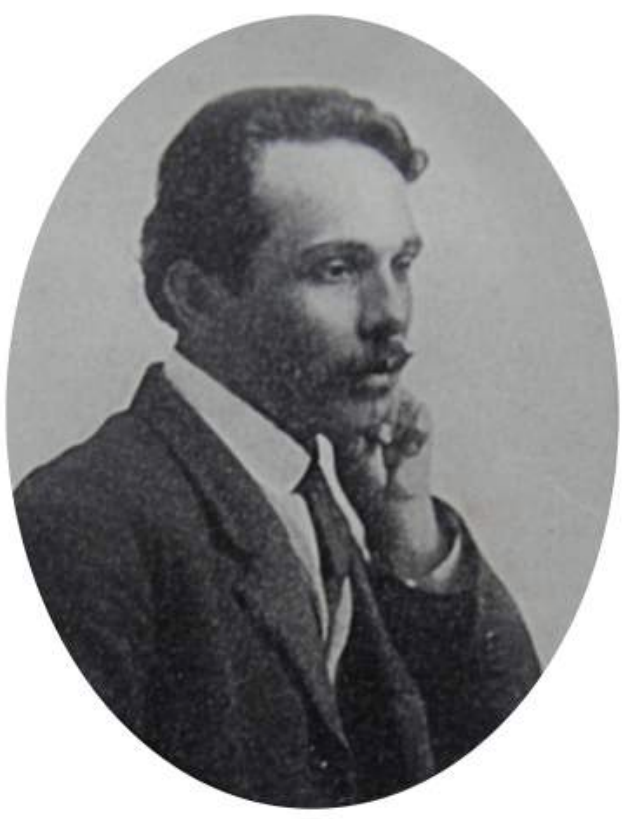
mano del estilo modernista para abundar en densos niveles de expresión del deseo amatorio alrededor de la figura de Susana y su historia.

El texto de Chavarría se ubica en Babilonia, y comienza cuando se está en una fiesta en honor de la faraona egipcia Nitocris, lo cual provocó una gran aglomeración de personas. En un determinado momento, en el atrio del templo de Bel, dos ancianos jueces: Soreb y Moadbed esperan la sentencia del Sumo Sacerdote ante sus acusaciones de adulterio proferidas contra la casta Susana, quien es presentada como un modelo de belleza, lo cual provoca el efecto erótico que propone el orientalismo sobre las mujeres de esas regiones: "El nácar del pudor embellecía su

Foto 5: Lisímaco Chavarría en 1910. En: Revista América. Año IV, número 1, enero de 1910, página 269 hechicera faz; llevaba suelto del cabello, el cual le caía encima de los hombros, y cuando elevaba sus ojos hacia el cielo, tenían el brillo esplendoroso de los astros." (I: 228). Esta erotización del discurso narrativo es acentuada al ofrecer el texto la información de que Susana venía envuelta solamente en una sábana blanca, puesto que estaba en el baño cuando la prendieron sus perseguidores. De esta manera, el cuento nos ofrece a una hermosa joven cuya desnudez es atenuada por la

\footnotetext{
${ }^{12}$ Véase el relato en Daniel 13; 1-64, en: La Biblia. Madrid: Editorial Verbo Divino, 2005, 1123-1125.
} 
sábana, símbolo de pureza, imagen límite que oscila entre el pecado y la castidad, tan recurrente en las construcciones femeninas de la mujer en la literatura del siglo XIX y principios del $\mathrm{XX}$.

Cuando ella llega, la muchedumbre pide que se apedree a la adúltera, ante lo cual reacciona Daniel e interroga a Susana; ella le dice que lea su inocencia en su conciencia, y le confiesa que su acusación se debe a que no ha cedido ante la seducción planteada por los dos ancianos. Nuevamente el relato se convierte en un texto sobre el erotismo. Daniel, comparando a Susana con una flor azotada por el viento (otra vez la imagen de la mujer objeto de belleza) le dice que la defenderá. Aquí el texto efectúa una comparación entre Daniel e Hipérides, cuando este último salvó a la hetaira Friné:

El tribuno Hipérides, defendiendo a la bella Friné, acusada por Euthias de profanadora del templo de Ceres, antes los Héliastes helenos, no fue más elocuente que Daniel ante aquel populacho sin bridas. (I: 229).

Este intertexto activa el componente erótico vinculado con Susana, puesto que la analoga a Friné, una famosa prostituta griega célebre por su belleza, la cual fue amante de Praxíteles, a quien sirvió de modelo para sus estatuas de Afrodita. Cuando fue acusada de impiedad, el orador Hipérides la defendió, desnudándola frente a sus jueces para que vieran que sí se parecía a la diosa. Con esta demostración, la hetaira fue absuelta.

En el caso de Susana, fue la demostración de Daniel, en el sentido de que los jueces mentían, lo que salvó a Susana. Daniel los convocó a testificar por separado, y ambos se contradijeron en cuanto al lugar donde supuestamente habían visto pecar a Susana. Los que levantaron falso testimonio fueron condenados a morir despedazados por las fieras.

Esta construcción de un discurso erótico sustentado sobre la base de un relato bíblico está también presente en el cuento "El Bautista", que textualiza la historia de Salomé y su malvada madre Herodias, argumento que ha tenido amplia recepción en la historia literaria. ${ }^{13}$ Lisímaco Chavarría no escapó a la seducción de este

\footnotetext{
${ }^{13}$ Véase, al respecto: Sara López Abadía 1988: 125-133; Daniel Bonilla Cerezo 2003: 159 179; Jin Danfeng 2014: 17-27. Tampoco esta leyenda le resultó indiferente a Rubén Darío, quien en su "Canción de otoño en primavera" expresa: "Yo era tímido como un niño. / Ella, naturalmente, fue,/ para mi amor hecho de armiño, /Herodías y Salomé... (1977: 271).
} 
discurso sobre la belleza de una joven que sirve a los propósitos sanguinarios de su propia madre.

En el texto bíblico, Herodes da una fiesta por su cumpleaños y Salomé baila para él. Gusta tanto el baile al primer personaje que le ofrece lo que ella quiera. A recomendación de Herodías, Salomé pide la cabeza de Juan el Bautista; Herodes no puede negársela por el ofrecimiento público, así que un verdugo entrega la cabeza de Juan en una bandeja de plata a la joven. Luego los discípulos recogen el cuerpo y lo entierran. ${ }^{14}$

En el relato de Chavarría, Juan Bautista se encuentra con Herodes Antipas y su amante y cuñada Herodías en las márgenes de un río. La pareja viaja en un lujoso carruaje y se detienen al ver al Bautista, el cual era admirado por Herodes. Desde ese momento, el narrador se ocupa de la descripción de la mujer a quien asocia con el demonio por su belleza y su maldad; de su físico destaca sus formas: "Voluptuosa como una hetaira griega, y atrayente cual las diosas paganas inmortalizadas en mármoles de Parros por los artífices helenos" (I: 232), y la describe como "un espíritu maléfico encarnado en su cuerpo de rosas y azucenas." (I: 232).

Nótese que desde ese momento inicial del relato, el lenguaje lisimaquiano se distancia de tradición bíblica para articular un discurso que recurre a la tradición grecolatina para efectuar sus comparaciones y valoraciones de la mujer. Igual procedimiento efectúa en el cuento "Susana", cuando es la biblioteca clásica pagana la que le provee las herramientas para sus valoraciones del personaje bíblico. Estamos en presencia de esas construcciones híbridas propias del modernismo hispanoamericano y de la asunción que de dicho canon realiza el propio Chavarría. En el caso de Herodía, esta dimensión intertextual insiste en erotizar su cuerpo, aunque tal procedimiento incurra también en la narración de cómo el Bautista reprende a Herodes por tomar de amante a su cuñada. Sin embargo, en el relato domina el discurso erótico referido a las mujeres (madre e hija) antes que el moralizante de Juan. Obsérvese la representación de Salomé, quien cuando entra al salón de la fiesta y baila es comparada por el narrador con Venus:

Sus formas de alabastro palpitaban al ritmo de los delicados giros del baile; sus ojos -libélulas azules- despedían fulgores que llenaban de ansias lúbricas a todos los patricios del festín. En el tejer de la danza, semejaba la hija de Herodías el espíritu de la tentación

\footnotetext{
${ }^{14}$ Consúltese: Mateo 14: 1-12 y Marcos 6:14-29, en: La Biblia. Madrid: Editorial Verbo Divino, 2005, 1607 y 1684 .
} 
revestido con las formas de un arcángel, el beleño del mal en el cáliz de una rosa...

En habiendo dejado de danzar, desatose el cinturón que hacía resaltar sus caderas mórbidas, el cual cayó sobre la alfombra, y luego su peplo, quedando desnudo su cuerpo de Afrodita!! (I: 233).

Este clímax del baile no forma parte del relato bíblico, el cual solamente menciona que la joven bailó ante Herodes. En su recreación de la escena, Chavarría coloca a Herodías como agente promotora del cuerpo de su hija. Le dice a los concurrentes: "¿Qué formas femeninas igualan a ese lirio inmaculado?" (I: 234).

Luego el narrador se extiende en valoraciones sobre la perfección del cuerpo de Salomé, a lo que sigue la posterior solicitud de la cabeza del Bautista, para concluir el relato con la risa macabra de Herodías, quien ve realizado su propósito de acabar con la vida de Juan.

A diferencia de estos dos relatos donde la relectura bíblica se convierte en motivo para el despliegue de un discurso altamente erótico sobre la representación femenina y, específicamente, del cuerpo de la mujer (nótese que en estos textos se presentan tres mujeres desnudas: Susana, Friné y Salomé), en los siguientes cuentos el interés se orienta a reforzar los modelos éticos y morales planteados por el Cristianismo, debido a la presencia en ellos de la figura de Jesucristo.

De esta manera, en "Magdalena" convive la hibridación orientalista del discurso con la propuesta de transformación del pecado. En el primer ámbito, el texto plantea todo un espacio narrativo de riqueza y placer donde habita el personaje, con el fin de mostrar su capacidad de renuncia al mundo material:

\footnotetext{
La elegante castellana de Magdalo acababa de dejar su lecho de plumas y sedas de Damasco. Aún se hallaba su regia estancia saturada con los perfumes del día anterior; en los pebeteros de ónix ardían las resinas que sus esclavas habían encendido la víspera y se veían restos de licores color de ámbar en copas de cristal de Alejandría, que dejaron los adoradores de la Flor de Betania, como era llamada en toda Galilea la hermana de Lázaro y Marta. (I: 235).
}

Sin embargo, ese día ella amaneció con una gran inquietud porque supo de la presencia de Jesús en la ciudad. Napir, su esclavo, le indica que ha visto al Nazareno y que le prometió visitarla. Pocos minutos después, se presenta Jesús a la casa de Magdalena y la reprende por haber abandonado la casa de su padre por el libertinaje, le dice que vuelva donde su familia y deje su vida de pecado. Ella cae a sus pies y le pide perdón, con lo cual 
su vida da un giro, regresa a su antigua casa y se transforma en fiel seguidora del Maestro.

Otro tanto ocurre en el cuento "El buen ladrón", que relata la vida pecaminosa de Dimas y Gestas, los dos ladrones que acompañaron a Jesús en la crucifixión. El texto inicia cuando Dimas recorre un solitario camino de Palestina para llegar a planear con su banda de delincuentes el asalto a la caravana del Rey de Egipto, quien pronto pasaría por allí. El léxico del relato es igualmente estilizado, de acuerdo con el canon modernista, pero esta estilización, en este caso, se refiere al paisaje: "El sol agonizaba en los confines occidentales de Jericó; lampos de oro brillaban en el azul espacio, y grandes pinceladas de minio en poniente..." (I: 239). En este escenario esplendoroso, se produce el asalto que, sin dificultades, ejecutan los bandoleros. Dimas había dado la orden de que se respetara a las mujeres, los niños y los ancianos; a pesar de ello, Gestas decide apropiarse de la reina, con lo cual tiene un enfrentamiento con su jefe, quien la libera. Por ello Gestas decide esperar a Dimas y asesinarlo. Cuando ambos se enfrentan, Dimas está a punto de apuñalar a su compinche, pero se le aparece Jesús y le dice que no puede matarlo porque ambos están destinados a acompañarlo en la crucifixión. Cuando Dimas escucha la voz del Maestro, deja el puñal, abandona el bosque y se va a entregar a Poncio Pilato, para esperar su ejecución al lado de Jesucristo.

"En Gethsemaní", se da continuidad a ese anuncio de la muerte de Jesús, ya que el texto cuenta cómo Cristo con tres de sus discípulos va al Huerto de ese sitio para orar a su padre con el fin de que le dé fuerzas para afrontar las torturas que se avecinan. Luego de efectuar esta oración, se le aparece un arcángel quien le entrega una copa con licor divino y le dice que ese líquido es un envío de Dios para que tenga valor. Después de esto "Judas, el discípulo más querido del Maestro, llega a él seguido de una multitud a la cual el terrible traidor había dado esta indicación: 'A quien yo bese, él es, prendedle."' ( I: 242-243). Y, efectivamente, Judas besa a Jesús y el hijo de Dios es atrapado y conducido a casa de Caifás para su tortura y muerte.

La historia de la pasión y muerte de Cristo finaliza en el relato "En el Tabor", donde se presenta a los discípulos luego de transcurridos cuarenta días de la resurrección. Subido en una nube y rodeado de ángeles los exhorta a que enseñen su doctrina y sigan su ejemplo. Luego, empieza su ascensión al cielo. Una vez que se ha ido, dos ángeles se aparecen a los discípulos y les indican que Jesús algún día volverá a la tierra; los apóstoles, 
después de escuchar a los enviados de Dios, se enrumban a la ciudad de Jerusalén. De esta manera concluyen las fantasías bíblicas de Lisímaco Chavarría.

\section{CONCLUSIÓN}

La narrativa de Chavarría Palma es un entramado discursivo que articula tres orientaciones: el costumbrismo, relatos de carácter orientalista y textos que hacen relecturas de pasajes bíblicos.

Los textos costumbristas verosimilizan tradiciones que el autor consideraba importantes de ser fijadas como representantes de referentes identitarios, por ello este tipo de relatos recurre a la estrategia de la selección de imágenes fotográficas para heredarlas a la posteridad. También es fundamental en los cuentos costumbristas analizados la mostración de la creencia comunal y su expresión anónima, con el fin de ocultar la elaboración individual, por parte del narrador, de los acontecimientos que enuncia y su atribución a una voz colectiva y sin autoría. De esta manera, los textos costumbristas se convierten en fieles representaciones del imaginario sobre una Costa Rica idílica, de un pasado que debe ser conocido por las futuras generaciones.

Los cuentos de la segunda orientación, echan mano de otro registro trabajado por el modernismo, la elaboración de imágenes de una otredad exótica y distante, que en el caso de Chavarría, fue una fuente libresca, antes que producto de sus propias experiencias de viaje. Este orientalismo constituye en el autor ramonense un conjunto de escenarios para mostrar el extrañamiento ante realidades imaginadas como maravillosas. Asimismo, este tipo de registro permite a Chavarría el despliegue de una serie de referencias eruditas de herencia grecolatina, fuente privilegiada para el modernismo de su tiempo.

La última serie narrativa, la que relee el texto bíblico, comporta dos dimensiones tal como se ha indicado. En primer lugar, una exotización de los personajes y un aprovechamiento del discurso de La Biblia para transgredirlo en cuanto a la representación femenina, puesto que dichos actantes son altamente erotizados mediante los dispositivos del estilizado lenguaje modernista de carácter parnasiano que está presente en estos relatos. En segundo lugar, la relectura bíblica desarrolla los ejemplos morales exaltando los paradigmas de comportamiento de los personajes que están al lado de Jesucristo, y del mismo Maestro, cúspide de la bondad y del sacrificio por la humanidad. 
La narrativa de Lisímaco Chavarría, a pesar de su brevedad comparada con su trabajo poético, es altamente productiva y muestra las preocupaciones de los narradores modernistas y costumbristas de principios del siglo $X X$, quienes observaron la narrativa en tanto un entramado discursivo propicio para registrar la memoria histórica y un espacio de experimentación estética que echó mano de las fuentes más legitimadas de su momento histórico.

\section{BIBLIOGRAFÍA}

Banús, Enrique. (2005). "La fuerza de la Biblia en la literatura." Gonzalo Aranda y Juan Luis Caballero. (Eds.) La Sagrada Escritura, palabra actual. XXV Simposio Internacional de Teología de la Universidad de Navarra. Servicio de Publicaciones de la Universidad de Navarra, 97-113.

Bonilla Cerezo, Daniel. (2003). "Salomé danza ante los tretrarcas modernistas: Valle Inclán y Castelao". AnMal. XXVII: 159-179.

Brox, Luis María. (1975). "Los límites del costumbrismo". Mester 5.2: 101-104.

Carvajal Milena, Antonio. (2004). "Consideraciones sobre la métrica en La Copa del Rey de Thule". José Andújar Almansa y José Luis López Bretones. (Eds). Villaespesa y las poéticas del modernismo. Almería: Universidad de Almería: Fundación Unicaja: Ayuntamiento de Almería, España, 157-175.

Chavarría Palma, Lisímaco. (2013). Obras completas. Tomos I y II. San José: Editorial de la Universidad de Costa Rica.

Chevalier, Jean et Alain Gheerbrant. (1999). Dictionaire des symboles. Paris: Éditions Robert Laffont.

Cuvardic García, Dorde. (2008). "La construcción de tipos sociales en el costumbrismo latinoamericano". Revista de Filología y Lingüística. XXXIV.1: 37-51.

Danfeng, Jin. (2014). "Salomé en la literatura y la música". Philoloica Urcitana. 11. (Setiembre): 17-27. 
Darío, Rubén. (1977). Poesía. Caracas: Biblioteca Ayacucho.

Echeverría, Aquileo. (1980). "La vela de un angelito". Concherías. Tercera edición. San José: Editorial Costa Rica.

Escobar, José. (1983). “El sombrero y la mantilla: moda e ideología en el costumbrismo romántico español". Revisión de Larra .¿Protesta o revolución?, 161-165. Recuperado de Biblioteca Virtual Universal. www.biblioteca.org.ar/LIBROS/89863.pdf. Consulta: 3 de noviembre de 2015.

Fuertes Manjón, Roberto. (1997). "La obra novelística de Rubén Darío y la narrativa centroamericana". Rubén Darío, La creación, argumento poético y expresivo. Anthropos. 170-171. (Enero-abril): 114-117.

González, Aníbal. (2006). "La prosa modernista". Roberto González Echevarría y Enrique Pupo-Walker. (Eds.). Historia de la literatura hispanoamericana II. El siglo XX. Trad. de Ana Santonja y Consuelo Triviño. Madrid: Gredos, 95-137.

Kirkpatrick, Susan. (1978). "The ideology of Costumbrismo". Ideologies and Literature. 1: 28-44.

Lasarte Valcárcel, Javier. 1997. "Ciudadanías del costumbrismo en Venezuela". Revista Iberoamericana. LXIII. 178-179. (Enero-junio): 175-184.

Laure, Anne. (1998). "De l'Ut pictura poesis à la fusion romantique des arts". Joëlle Caullier. (Ed). La synthèse des arts. Lille: Presses du Septentrion. Recuperado de https://hal.archives-ouvertes.fr/hal00560739. Consulta: 3 de noviembre de 2015.

López Abadía Arroita, Sara. (1988). "Salomé, un mito literario finisecular: de Flaubert a Oscar Wilde". Estudios de lengua y literatura francesas. 2, 125-133.

Moreiro, Julián. (2000). Introducción a Costumbristas de Hispanoamérica, Cuadros, leyendas y tradiciones. Antología y edición de Julián Moreiro. Madrid: EDAF, 11-41. 
Nagy-Zekmi, Silvia. (2008). "Introducción: "Buscando el Este en el Oeste: prácticas orientalistas en la literatura latinoamericana". Silvia Nagy-Zekmi. (Ed.) Moros en la costa. Orientalismo en Latinoamérica. Madrid: Iberoamericana - Vervuert, 11-24.

Picado Gätgens, Olga. (1991). "Imagen y costumbrismo: tradición metatextual." Kañina. 15.1-2. (Enero-diciembre): 222-226.

Pupo-Walker, Enrique. (1978). "El cuadro de costumbres, el cuento y la posibilidad de un deslinde." Revista Iberoamericana. 44. 102: $1-15$.

Quesada Soto, Álvaro. (1995). La formación de la narrativa nacional costarricense (1890-1910). San José: Editorial de la Universidad de Costa Rica.

Rodríguez Cascante, Francisco. (2013). "Estudio introductorio". Lisímaco Chavarría. Obras completas. Tomo I. San José: Editorial de la Universidad de Costa Rica, 1-137.

Román, Isabel. (1988). "Hacia una delimitación formal del costumbrismo decimonónico". Philologia hispalenses. 3: 167-179.

Roque Baldovinos, Ricardo. (1997). "Actualidad de Salarrué: un diálogo crítico". Cultura. 78 (enero-abril): 25-40.

Roque Baldovinos Ricardo. (2009). "Exotismo y autoridad cultural modernista: dos viajeros centroamericanos por el extremo oriente." Valeria Grinberg Pla y Ricardo Roque Baldovinos. (Eds.) Tensiones de la modernidad: del modernismo al realismo. Guatemala: F \& G Editores, 167-188.

Rubio Cremades, Enrique. (1983). "Costumbrismo y novela en la segunda mitad del siglo XIX." Anales de literatura española. Universidad de Alicante, 457-472.

Said, Edward. (1990). Orientalismo. Trad. de María Luisa Fuentes. Madrid: Libertarias.

Sandoval, Adriana. (1992). "El costumbrismo de Rafael Delgado en La Calandria." Literatura Mexicana. 4. 1: 7-25. 
Varios autores. (2005). La Biblia. Madrid: Editorial Verbo Divino. 